\title{
Editorial: Flexible and Active Distribution Networks
}

\author{
Peng $\mathrm{Li}^{1}$, Yang $\mathrm{Mi}^{2}$, Nian $\mathrm{Liu}^{3}$, Yue Zhou ${ }^{4}$, Hao $\mathrm{Yu}^{1}$ and Haoran $\mathrm{Ji}^{1 *}$ \\ ${ }^{1}$ School of Electrical and Information Engineering, Tianjin University, Tianjin, China, ${ }^{2}$ School of Electric Power Engineering, \\ Shanghai University of Electric Power, Shanghai, China, ${ }^{3}$ School of Electrical and Electronic Engineering, North China Electric \\ Power University, Beijing, China, ${ }^{4}$ School of Engineering, Cardiff University, Cardiff, United Kingdom
}

Keywords: active distribution network, distributed generator, flexible distribution device, operational flexibility, operation and planning

Editorial on the Research Topic

Flexible and Active Distribution Networks

\section{INTRODUCTION}

With the increasing penetration of distributed generators (DG), distribution networks are gradually transforming from passive networks to active distribution networks (ADN) (Ji et al., 2019a). However, the intermittent power generation of DGs has significant uncertainties in spatial and temporal distribution. These uncertainties bring challenges and put forward higher requirements for operational flexibility in ADN (Mi et al., 2019). Simultaneously, accurate and fast power flow control by flexible distribution devices, represented by soft open point (SOP) (Bloemink and Green, 2010), solid transformer, distribution unified power flow controller, can significantly improve the operational flexibility of ADNs. The wide application of power electronic devices provides opportunities for the further improvement on the performances of distribution networks (Lee et al., 2019).

This Research Topic is organized to introduce the recent progresses on the modeling, simulation, operation and planning of ADNs with various flexible distribution equipment (power electronic devices). Finally, fifteen papers have been accepted for this Research Topic, which can be sorted into the following three categories including 1) Efficient modeling, simulation and analysis methods; 2) Operation control and energy management under uncertainties; 3) Flexibility and resilience evaluation and enhancement. The three sections below respectively introduce the major researches and contributions of the papers covered in each category.

Specialty section: This article was submitted to Smart Grids,

a section of the journal Frontiers in Energy Research

Received: 29 March 2021

Accepted: 24 May 2021

Published: 04 June 2021

Citation:

LiP, Mi Y, Liu N, Zhou Y, Yu H and Ji H (2021) Editorial: Flexible and Active

Distribution Networks.

Front. Energy Res. 9:687129. doi: $10.3389 /$ fenrg.2021.687129

\section{Efficient Modeling, Simulation and Analysis Methods}

Mathematically, the optimal operation of distribution networks generally belongs to largescale, non-convex and non-linear optimization problems. The integration of power electronic devices in ADNs also increases the complexities in modeling, simulation and analysis ( $\mathrm{Li}$ et al., 2017). It is necessary to develop efficient methods for optimal operation and control issues in ADNs.

Fu et al. propose an optimal power flow calculation method for the three-phase four-wire lowvoltage distribution system. Through improving the node admittance matrix, the complexity of problem solving is effectively reduced.

Li et al., 2017 establish an analysis model to evaluate the wind power consumption capacity. The influence of adjustable parameters on the consumption capacity is quantitatively analyzed. 
Li et al., 2017 present a positive sequence voltage fault component polarization impedance criterion. It can adaptively follow the fault resistance variation with less affected by the fault response characteristics of inverter interfaced DGs.

Sun et al. develop a linearized model for modular multilevel converter (MMC) considering diverse failure scenarios. Then, an analytical calculation method is proposed to solve the problem of single-pole grounding short-circuit.

Wang et al. design the DG-load matching degree and the accommodation ratio to analyze DG accommodation in ADN. The simulation model of sequential production is further proposed to calculate the DG-network-load accommodation ratio.

\section{Operation Control and Energy Management Under Uncertainties}

The integration of volatile DG and various demand-side resources with uncertainties makes the operation more complex and challenging (Liu et al., 2018). Thus, it is important to investigate the optimal control and energy management methods to deal with the uncertainties (Ma et al., 2019).

Hu et al. develop a two-stage framework for complementary power generation of wind, hydropower and pumped storage systems. The forecast evolution model is established to describe the uncertainties of wind power in different regions.

Luo et al. present a bi-level dispatch model based on virtual power plants (VPPs), which arranges DGs, ESSs and demand response resources as a VPP. VPPs are utilized to alleviate the peak load level of distribution systems.

Song et al. develop a coordinated stochastic scheduling model of integrated electricity and natural gas systems to address the uncertainty of DGs and loads. It helps to accommodate wind power and provide additional flexible ramping capacities.

Qazi et al. utilize cooperative game theory for the optimal operation of isolated microgrid-clusters. To mitigate uncertainties from DGs and loads, the frequency is regulated in real-time and a dynamic droop control process is adopted.

Wang et al. consider load aggregators (LAs) and ADNs as two stakeholders and adopt a distributed method to establish different economic optimization goals.

\section{Flexibility and Resilience Evaluation and Enhancement}

Flexibility and resilience enhancement are increasingly important for the operation of ADN (Parvania et al., 2020). Meanwhile, the

\section{REFERENCES}

Bloemink, J. M., and Green, T. C. (2010). Increasing Distributed Generation Penetration Using Soft Normally-Open Points, July 25-29, 2010, Minneapolis, MN, IEEE Power and Energy Society General Meeting. Providence, RIPiscataway, NJ: IEEE. doi:10.1109/pes.2010.5589629 quantitative evaluation of flexibility and resilience has become a major concern for the system operation (Ji et al., 2019b).

Cai et al. propose a reliability calculation model with ESS integration. The impacts of different prices and incentive policies are analyzed for flexibility and reliability improvement.

Hou et al. present an improved reliability evaluation approach of ADN. The impact increment method and shadow price are adopted to address the high penetration level of renewable energy.

Huo et al. design a multi-station topology to realize the flexible connection of distribution networks. A coordinated control strategy is proposed to ensure the reliable and efficient operation of multi-station system.

Wang et al. develop an operation strategy for SOP-based ESSs with the consideration of battery life. ESSs are regulated to promote DG penetration and reduce the operational cost of ADNs.

Xing et al. propose an optimal dispatch model to facilitate DG integration. Multiple devices are coordinated and the benefits for dispatchable resources are considered in a multi-objective framework.

\section{CONCLUSION}

The papers in this Research Topic cover various technical solutions for flexible operation problems of distribution networks, such as the efficient analytical methods with high penetration of DG, flexible operation methods under uncertainties, and system planning with flexible distribution devices. The research will facilitate the enhanced flexibility, efficiency, and reliability of distribution networks under complex environments brought by high DG penetration.

\section{AUTHOR CONTRIBUTIONS}

All authors listed have made a substantial, direct, and intellectual contribution to the work and approved it for publication.

\section{ACKNOWLEDGMENTS}

Authors would like to acknowledge the National Natural Science Foundation of China (U1866207, 61873159, 52007131, 51907139), and National Key Research and Development of China (2018YFB1503001), which have made this Frontiers Research Topic possible.

Ji, H., Wang, C., Li, P., Ding, F., and Wu, J. (2019a). Robust Operation of Soft Open Points in Active Distribution Networks with High Penetration of Photovoltaic Integration. IEEE Trans. Sustain. Energ. 10 (1), 280-289. doi:10.1109/TSTE.2018.2833545

Ji, H., Wang, C., Li, P., Song, G., Yu, H., and Wu, J. (2019b). Quantified Analysis Method for Operational Flexibility of Active Distribution Networks with High Penetration of Distributed Generators. Appl. Energ. 239, 706-714. doi:10.1016/ j.apenergy.2019.02.008 
Lee, T., Zhou, Y., Chao, L., Jianzhong, Wu., and Nick, J. (2019). A General Form of Smart Contract for Decentralized Energy Systems Management. Nat. Energ., 4 (2), 140-149. doi:10.1038/s41560-018-0317-7

Li, P., Ji, H., Wang, C., Zhao, J., Song, G., Ding, F., et al. (2017). Coordinated Control Method of Voltage and Reactive Power for Active Distribution Networks Based on Soft Open point. IEEE Trans. Sustain. Energ. 8 (4), 1430-1442. doi:10.1109/TSTE.2017.2686009

Liu, N., Cheng, M., Yu, X., Zhong, J., and Lei, J. (2018). Energy-Sharing Provider for PV Prosumer Clusters: A Hybrid Approach Using Stochastic Programming and Stackelberg Game. IEEE Trans. Ind. Electron. 65 (8), 6740-6750. doi:10.1109/ TIE.2018.2793181

Ma, L., Liu, N., Zhang, J., and Wang, L. (2019). Real-time Rolling Horizon Energy Management for the Energy-Hub-Coordinated Prosumer Community from a Cooperative Perspective. IEEE Trans. Power Syst. 34 (2), 1227-1242. doi:10. 1109/TPWRS.2018.2877236

Mi, Y., Chen, X., Ji, H., Ji, L., Fu, Y., Wang, C., et al. (2019). The Coordinated Control Strategy for Isolated DC Microgrid Based on Adaptive Storage
Adjustment without Communication. Appl. Energ. 252, 113465. doi:10.1016/ j.apenergy.2019.113465

Parvania, M., Bindner, H. W., and Qadrdan, M. (2020). Guest Editorial: Maximising Flexibility through Energy Systems Integration. IET Energ. Syst. Integration 2 (2), 67-68. doi:10.1049/iet-esi.2020.0054

Conflict of Interest: The authors declare that the research was conducted in the absence of any commercial or financial relationships that could be construed as a potential conflict of interest.

Copyright (c) $2021 \mathrm{Li}, \mathrm{Mi}, \mathrm{Liu}, \mathrm{Zhou}, \mathrm{Yu}$ and Ji. This is an open-access article distributed under the terms of the Creative Commons Attribution License (CC BY). The use, distribution or reproduction in other forums is permitted, provided the original author(s) and the copyright owner(s) are credited and that the original publication in this journal is cited, in accordance with accepted academic practice. No use, distribution or reproduction is permitted which does not comply with these terms. 